MYU Tokyo

S \& M 1177

\title{
Solid Oxide Amperometric CO Sensor Prepared by DC Sputtering
}

\author{
Tatsumi Ishihara,,${ }^{1, *}$ Toshikazu Mori, ${ }^{1}$ Jun Iwata, ${ }^{1}$ Hidehisa Hagiwara,,${ }^{1,2}$ and Shintaro Ida ${ }^{1,2}$ \\ ${ }^{1}$ Department of Applied Chemistry, Faculty of Engineering, Kyushu University \\ Motooka 744, Nishi-ku, Fukuoka 819-0395, Japan \\ ${ }^{2}$ International Institute for Carbon-Neutral Energy Research (WPI-I2CNER), \\ Kyushu University, Motooka 744, Nishi-ku, Fukuoka 819-0395, Japan
}

(Received November 20, 2015; accepted January 28, 2016)

Keywords: solid oxide amperometric sensor, $\mathrm{CO}$ sensor, carbon neutral energy

An amperometric $\mathrm{CO}$ sensor using a solid oxide electrolyte was studied, and it was found that the oxygen pumping current increased with increasing $\mathrm{CO}$ concentration when $\mathrm{Au}(10 \mathrm{wt} \%) / \mathrm{In}_{1.9} \mathrm{Sn}_{0.1} \mathrm{O}_{3}$ and $\mathrm{RuO}_{2}(10 \mathrm{wt} \%)$ were used for cathode and anode, respectively, and $\mathrm{La}_{0.9} \mathrm{Sr}_{0.1} \mathrm{Ga}_{0.8} \mathrm{Mg}_{0.2} \mathrm{O}_{3}$ was used as the electrolyte. In this study, the electrode was prepared by DC sputtering. Although the morphology of the deposited electrode film was dense, the sensor responded sensitively to $\mathrm{CO}$ if the electrode was prepared by DC sputtering. Coating $\mathrm{RuO}_{2} / \mathrm{La}_{0.6} \mathrm{Sr}_{0.4} \mathrm{CoO}_{3}$ powder on a $\mathrm{RuO}_{2}$ electrode prepared by sputtering effectively increased sensitivity because of the increased surface area and oxidation activity, and a sensitivity to $\mathrm{CO}$ of ca. $19 \mu \mathrm{A} /$ decade was achieved, which is ca. 4 times higher than that of powder painted electrodes $(4.5 \mu \mathrm{A} /$ decade) at $673 \mathrm{~K}$ in our previous study [Sens. Actuators, B 223 (2016) 535].

\section{Introduction}

A selective and reliable $\mathrm{CO}$ sensor is highly important in various areas because of safety issues due to the high toxicity of CO. Therefore, several types of $\mathrm{CO}$ sensor have been proposed, and some are already commercially available. ${ }^{(1)}$ Among them, a semiconductor type sensor, namely, $\mathrm{SnO}_{2}$ modified with additives, is widely used for monitoring $\mathrm{CO}$ in rooms, ${ }^{(2-6)}$ and also solid electrolyte type sensors have also been widely studied. ${ }^{(7-12)}$ However, the most serious issue with the semiconductor-type sensor is low selectivity. Therefore, catalytic combustion-type and electrochemical-type $\mathrm{CO}$ sensors are also widely used for detection of $\mathrm{CO}$. In the case of electrochemical CO sensors, selective detection of $\mathrm{CO}$ can be achieved; however, maintenance of the sensor is required relatively often (at least once per year). Recently, the ability to detect CO in exhaust gas from a gas water heater has been strongly demanded after an accident caused by incomplete combustion. However, applying a semiconductor-type $\mathrm{CO}$ sensor which monitors the combustion state is very difficult, and there is an urgent requirement for the development of an alternative $\mathrm{CO}$ sensor that is highly selective and can detect $\mathrm{CO}$ directly in an exhaust gas line. ${ }^{(1)}$

To meet this demand, a CO sensor using a solid state electrolyte was proposed and studied intensively. ${ }^{(1)}$ Solid electrolyte-type gas sensors generally have better selectivity for the gas species of interest. Therefore, an $\mathrm{O}_{2}$ sensor using yttria- stabilized $\mathrm{ZrO}_{2}$ has been widely used for

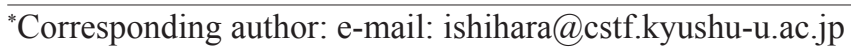


monitoring $\mathrm{P}_{\mathrm{O} 2}$ in engine exhaust gas. ${ }^{(1)}$ On the other hand, mixed potential type sensors have been attracting much attention recently because they offer a wider range of detectable gas species. ${ }^{(7)}$ To date, there have been many reports on mixed potential-type sensors. ${ }^{(8-12)}$ In our previous studies, we investigated the amperometric type sensor based on changes in the oxide ion pumping current in a $\mathrm{LaGaO}_{3}$-based oxide, and high sensitivity as well as selectivity was exhibited by this type sensor against $\mathrm{CH}_{4}, \mathrm{C}_{3} \mathrm{H}_{6}$, and $\mathrm{NO}$ based on the choice of electrode catalyst. ${ }^{(13-17)}$ The detection mechanism of this sensor was reported in our previous study. ${ }^{(14)}$ However, we applied $+1 \mathrm{~V}$ to the active electrode for oxidation, and oxygen was electrochemically pumped from the inactive to the active electrode to oxidize the sensed gas. Since the oxygen partial pressure on the active electrode was decreased by the oxidation reaction of the pumped oxygen, the driving force for oxygen pumping was increased, which caused the oxide ion current also to increase upon exposure to a gas like $\mathrm{CO}$. We noted that the electrode overpotential of the active electrode decreased upon exposure to $\mathrm{CO}$, which might have been caused by decreased $\mathrm{P}_{\mathrm{O} 2}$ around the active electrode. This may be another reason for increased oxygen pumping current when the sensor was exposed to $\mathrm{CO}$. In this study, we investigated the amperometric $\mathrm{CO}$ sensor based on the same detection mechanism, ${ }^{(17,18)}$ i.e., a combination of active and inactive electrode catalysts for $\mathrm{CO}$ oxidation. The effects of electrode deposition by sputtering were studied along with miniaturization and reproducibility of the sensor.

\section{Experimental Methods}

A solid electrolyte of $\mathrm{La}_{0.9} \mathrm{Sr}_{0.1} \mathrm{Ga}_{0.8} \mathrm{Mg}_{0.2} \mathrm{O}_{3}$ (denoted as LSGM) was prepared by sintering LSGM powder, which was prepared using a conventional solid state reaction method. ${ }^{(19,20)}$ The diameter and thickness of the disk were 17 and $0.4 \mathrm{~mm}$, respectively, unless otherwise noted. $\mathrm{RuO}_{2}$ and $\mathrm{Au} / \mathrm{In}_{1.9} \mathrm{Sn}_{0.1} \mathrm{O}_{3}$ (ITO) were deposited on each face of the LSGM disk by DC sputtering (Pascal Co. Ltd.). Dense disks of $\mathrm{RuO}_{2}$ and $\mathrm{Au} / \mathrm{ITO}\left(10 \mathrm{wt} \% \mathrm{Au} / \mathrm{In}_{0.927} \mathrm{Sn}_{0.073} \mathrm{O}_{1.5}\right)$ were used as the target of anode and cathode, respectively. Deposition of each electrode was performed at $773 \mathrm{~K}$ with 12 $\mathrm{W}$ constant power mode for $4 \mathrm{~h}$. The deposited electrode was square with a $5 \mathrm{~mm}$ length. After deposition of electrodes, Pt lead electrodes were deposited on each by DC sputtering, and Pt lead lines were connected to the Pt lead electrodes using Pt paste followed by calcining at $873 \mathrm{~K}$ for $1 \mathrm{~h}$. A schematic image of the prepared sensor element is shown in Fig. 1. To increase the sensitivity, $\mathrm{RuO}_{2} / \mathrm{La}_{0.6} \mathrm{Sr}_{0.4} \mathrm{CoO}_{3}$ (LSC) (1:9) was painted on the sputtered $\mathrm{RuO}_{2}$ electrode. ITO and LSC were also prepared by the solid state reaction method using metal nitrates or oxides as starting chemical reagents. Before preparation of a slurry, the electrode powder was calcined at $873 \mathrm{~K}$ for $6 \mathrm{~h}$.

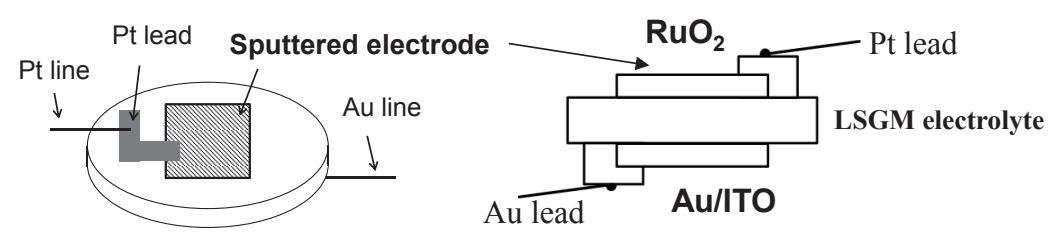

(a)

(b)

Fig. 1. Schematics of the prepared sensor element using Au/ITO and $\mathrm{RuO}_{2}$ electrodes: (a) top view and (b) crosssectional view. 
In the measurement assembly, the sensor element was placed in a gas flow chamber in which either reference air or sample CO (50-3000 ppm), which is made by mixing $1 \% \mathrm{CO}$ in $\mathrm{He}$ with air, was fed at $100 \mathrm{ml} / \mathrm{min}$. Change in current density was measured by the dc two-probe method, and $\mathrm{Pt}$ and $\mathrm{Au}$ wires were used as lead wires for the active and the inactive electrodes, respectively. $\mathrm{Pt}$ and $\mathrm{Au}$ meshes were also used as current correctors for the active and inactive electrodes, respectively, and were set on the lead electrode deposited by sputtering using commercial $\mathrm{Pt}$ and $\mathrm{Au}$ pastes. In the amperometric mode, $1 \mathrm{~V}$ dc was always applied using a potentiostat/galvanostat (Hokuto Denko HA301) as the $\mathrm{RuO}_{2}$ based electrode was always positive. The voltage and current were measured with a digital multimeter (Advantest, Model R645A) and/or digital electrometer (Advantest, Model R8240). The sensitivity of the sensor was defined as a current change against the CO concentration of one order of magnitude. The sensing property was measured several times with several elements and the reproducibility of the sensitivity was confirmed (Deviation of sensitivity is within 5\%).

\section{Results and Discussion}

Figure 2 shows scanning electron microscopy (SEM) images of Au/ITO electrodes prepared by DC and radio frequency (RF) sputtering. In both methods, an Au/ITO film was successfully deposited on an LSGM film, and EDX analysis suggested that the composition of the film was almost the same as $10 \mathrm{wt} \% / \mathrm{In}_{1.9} \mathrm{Sn}_{0.1} \mathrm{O}_{3}$. However, the morphology of the electrode differed between DC and RF sputtering. As shown in Fig. 2, a more dense and smooth morphology of the $\mathrm{Au} / \mathrm{ITO}$ electrode was obtained by DC sputtering compared with that from RF sputtering. A tighter contact was also achieved on the Au/ITO electrode deposited by DC sputtering. Therefore, we used $\mathrm{DC}$ sputtering for preparation of the $\mathrm{Au} / \mathrm{ITO}$ and $\mathrm{RuO}_{2}$ electrodes.

Figure 3 shows SEM images of the fractured surface of $\mathrm{Au} / \mathrm{ITO}$ and $\mathrm{RuO}_{2}$ electrodes. It is obvious that flat and uniform thicknesses of electrodes were deposited successfully by DC sputtering. Although a small gap was observed on the Au/ITO electrode, this could have been formed when fracturing the surface. The thickness of the deposited electrode was estimated to be
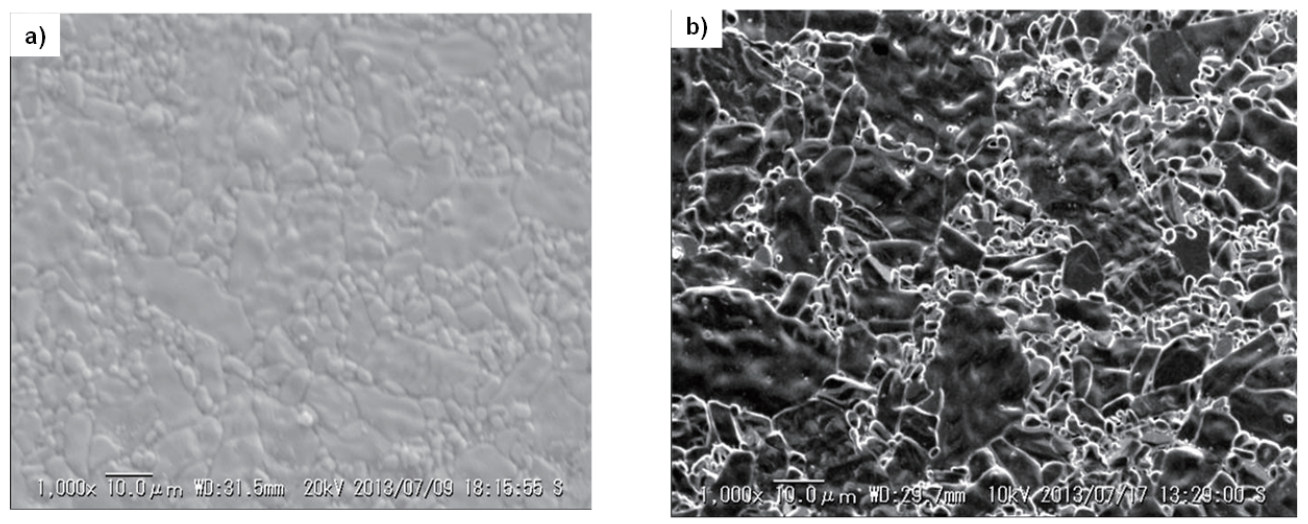

Fig. 2. SEM images of Au/ITO electrodes prepared by (a) DC and (b) RF sputtering. 

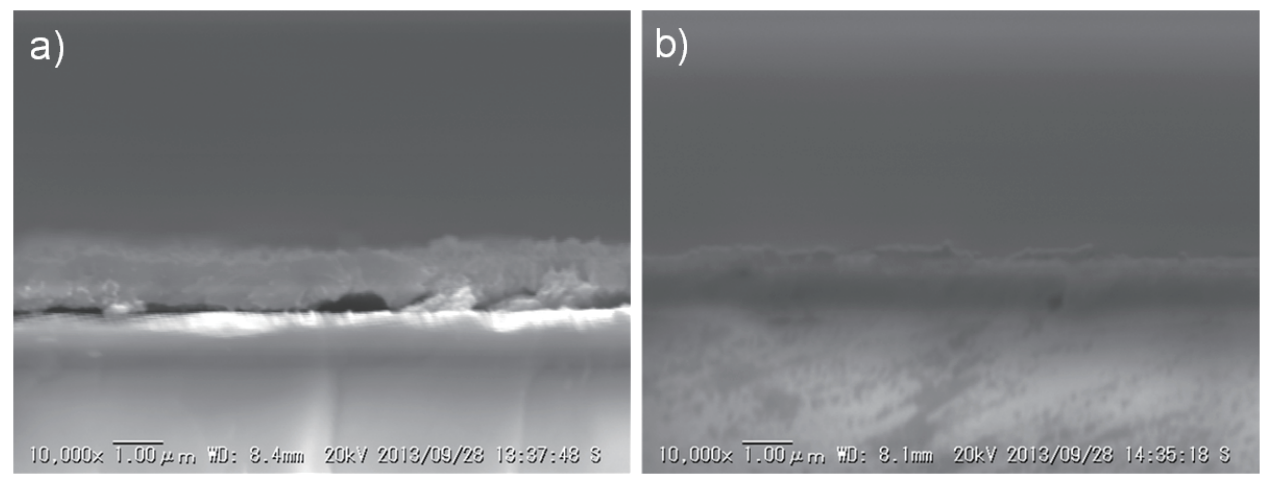

Fig. 3. SEM images of the fractured surface of (a) Au/ITO and (b) $\mathrm{RuO}_{2}$ electrodes.

ca. $1 \mathrm{~mm}$ for both $\mathrm{Au} / \mathrm{ITO}$ and $\mathrm{RuO}_{2}$ electrodes. It is also noted that a dense film was deposited on both electrodes in spite of the columnar shape that tends to be deposited in sputtering.

Figure 4 shows typical responses to $\mathrm{CO}$ at $773 \mathrm{~K}$ on the sensor with $\mathrm{RuO}_{2}$ and $\mathrm{Au} / \mathrm{ITO}$ film electrodes. Obviously, oxygen pumping current was increased upon exposure to $\mathrm{CO}$, and the change in current increased with increasing $\mathrm{CO}$ concentration. The increase in current upon exposure to $\mathrm{CO}$ on the sensor using the electrode deposited by sputtering is the same as that using $\mathrm{Au} / \mathrm{ITO}$ and $\mathrm{RuO}_{2} / \mathrm{LSC}$ prepared using the powder painting method. Therefore, the detection mechanism seems to be the same for both sensors. Figure 5 shows the current change of the sensor as a function of $\mathrm{CO}$ concentration at temperatures from 573 to $773 \mathrm{~K}$. At each temperature, it is obvious that oxygen pumping current increased with increasing $\mathrm{CO}$ concentration, so $\mathrm{CO}$ can be detected by observing the oxygen pumping current. The sensitivity to $\mathrm{CO}$ increased with increasing operating temperature, and at $773 \mathrm{~K}$, a sensitivity of $93.2 \mu \mathrm{A} /$ decade to $\mathrm{CO}$ was achieved. This sensitivity is 10 times larger than that of the sensor prepared by hand painting in our previous study. (21) In Fig. 5, the reproducibility of the sensor data is also shown, and it is obvious that reproducibility of the sensor is reasonably high. Considering the sensitivity, higher operating temperatures are suitable; however, even at $673 \mathrm{~K}$, it is obvious that reasonable linearity was observed between oxygen pumping current and $\mathrm{CO}$ partial pressure.

In our previous study, this type sensor was highly selective to CO; however, only oxygen strongly affects the oxygen pumping current. Therefore, the influence of oxygen on this sensor with electrodes deposited by sputtering was studied. Figure 6 shows the response to $\mathrm{O}_{2}$ of the sensor at $673 \mathrm{~K}$. Upon exposure to low partial pressure of oxygen, current was immediately decreased and then gradually increased. When the atmosphere was returned to air, the current returned to the original level after the overshoot. Impedance measurements suggested that this decrease in oxygen pumping current was caused by an increased overpotential of the Au/ITO electrode. However, the change in current due to $\mathrm{O}_{2}$ was not large for the sensor using Au/ITO and $\mathrm{RuO}_{2}$ electrodes prepared by sputtering. The current is shown in Fig. 6(b) as a function of oxygen partial pressure. In this figure, current change in response to $\mathrm{O}_{2}$ at $773 \mathrm{~K}$ is also shown. At $673 \mathrm{~K}$, dependence of current change on $\mathrm{P}_{\mathrm{O} 2}$ was not large, particularly, in a $\mathrm{P}_{\mathrm{O} 2}$ range higher than $10 \%$, which is the expected $\mathrm{P}_{\mathrm{O} 2}$ range for combustion control in small steam boilers. In contrast, at $773 \mathrm{~K}$, sensitivity to $\mathrm{O}_{2}$ was greatly increased ( $404 \mu \mathrm{A} /$ decade), so the optimum operating temperature for this sensor could be around $673 \mathrm{~K}$. 


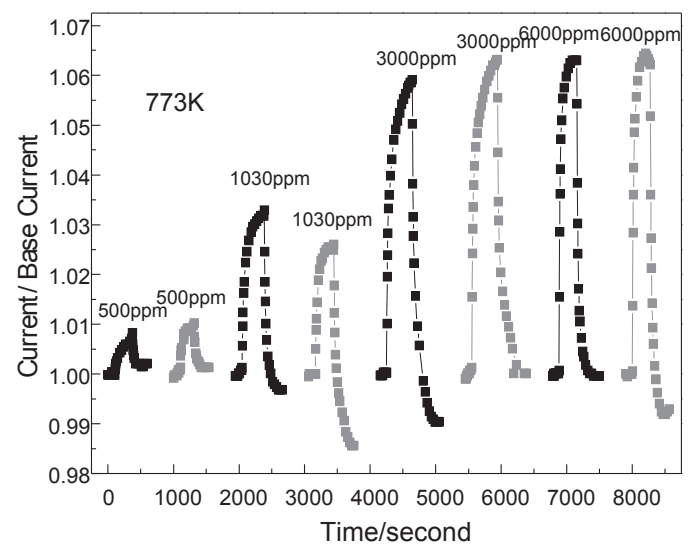

Fig. 4. Typical response to $\mathrm{CO}$ at $773 \mathrm{~K}$ on the sensor with $\mathrm{RuO}_{2}$ and $\mathrm{Au} / \mathrm{ITO}$ film electrodes. Black is the first response, and gray indicates the second trial for reproducibility.

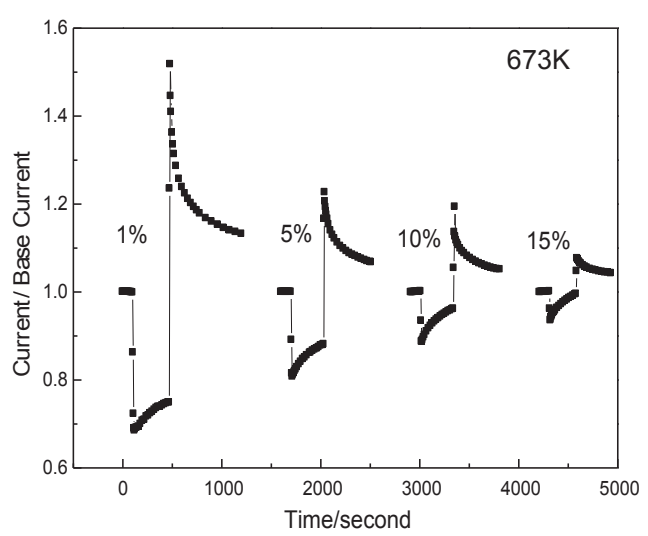

(a)

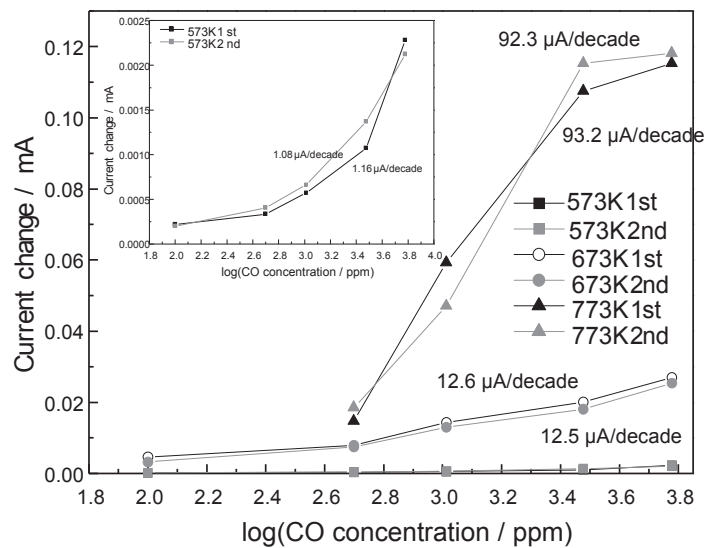

Fig. 5. Change in current of the sensor using $\mathrm{Au} /$ ITO and $\mathrm{RuO}_{2}$ as a function of $\mathrm{CO}$ concentration at temperatures from 573 to $773 \mathrm{~K}$. "1st" means response in the first trial, and " 2 nd" means response in the second trial for reproducibility.

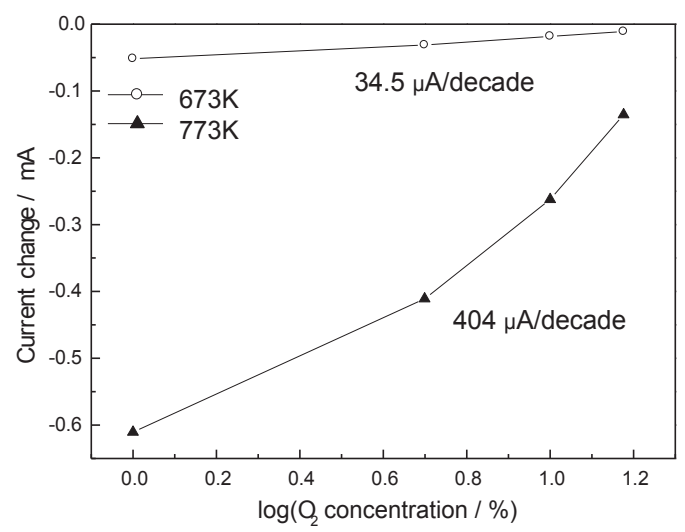

(b)

Fig. 6. (a) Response to $\mathrm{O}_{2}$ on the sensor at $673 \mathrm{~K}$ and (b) change in current of the sensor as a function of oxygen partial pressure from 573 to $773 \mathrm{~K}$.

To increase sensitivity to $\mathrm{CO}$, coating the $\mathrm{RuO}_{2}$ electrode with $\mathrm{RuO}_{2} / \mathrm{LSC}$ powder was investigated. A schematic image of the sensor is shown in Fig. 7. A powder of $\mathrm{RuO}_{2} / \mathrm{LSC}$ was hand-painted on the Pt lead wire deposited on the $\mathrm{RuO}_{2}$ film electrode. After coating, the sensor was calcined at $873 \mathrm{~K}$ for $30 \mathrm{~min}$ before measurement. Figure 8(a) shows a typical response curve to $\mathrm{CO}$ for this sensor at $773 \mathrm{~K}$. It is obvious that the oxygen pumping current was increased and returned to its original level within $60 \mathrm{~s}$ after expose to $\mathrm{CO}$ and air. Therefore, considering the time required to exchange the atmosphere in the measurement chamber, the response of this sensor was reasonably fast. We also observed that the change in oxygen pumping current increased with increasing CO partial pressure. However, at $6000 \mathrm{ppm} \mathrm{CO}$, which is an excessively high 


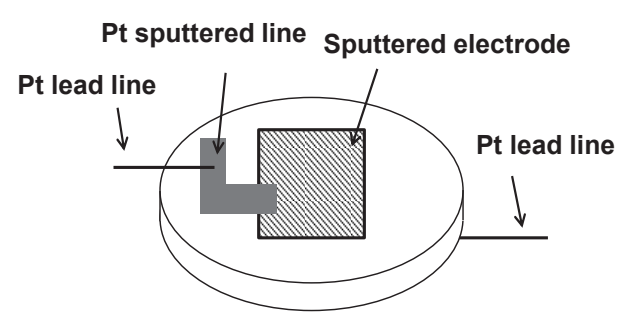

(a)

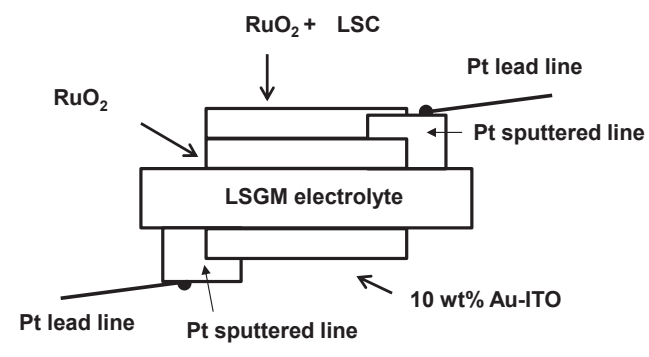

(b)

Fig. 7. Schematics of the sensor with $\mathrm{RuO}_{2} / \mathrm{LSC}$ powder coated on $\mathrm{RuO}_{2}$ : (a) top view and (b) cross-sectional view.

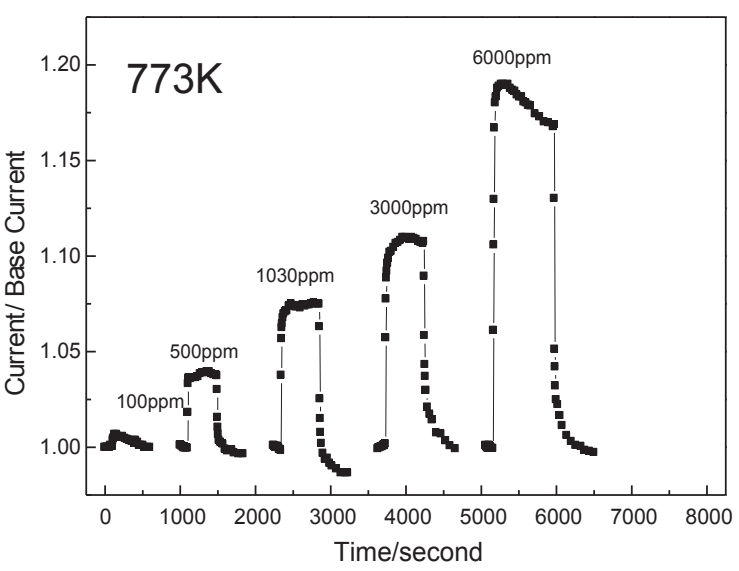

(a)

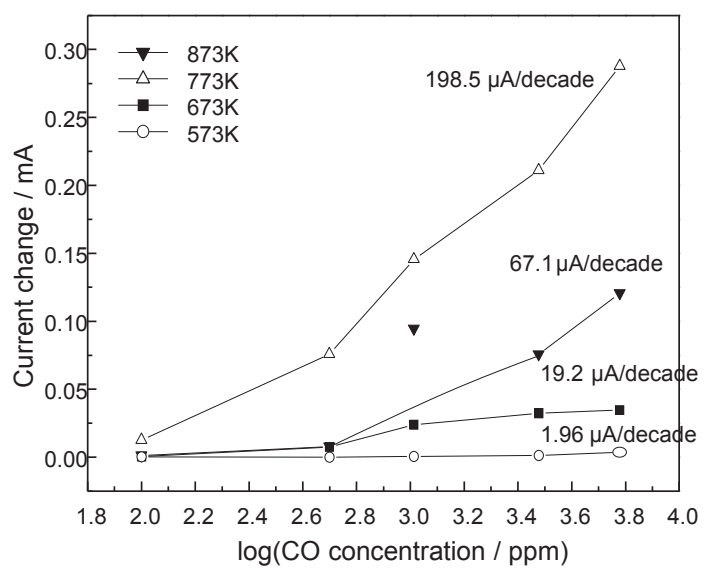

(b)

Fig. 8. (a) Typical response curve to $\mathrm{CO}$ of the sensor using $\mathrm{RuO}_{2} / \mathrm{LSC}$-coated $\mathrm{RuO}_{2}$ and $\mathrm{Au} / \mathrm{ITO}$ electrodes at $773 \mathrm{~K}$. (b) Oxygen pumping current as a function of $\mathrm{CO}$ from 673 to $873 \mathrm{~K}$.

concentration, the current achieved a maximum and gradually decreased with time, i.e., the socalled annealing phenomena in the response was observed. This may be explained by the reaction of $\mathrm{CO}$ with the active oxygen initially existing on the surface of the $\mathrm{RuO}_{2}$ film electrode followed by using oxygen, which was supplied by the electrochemical pump. The relationship between oxygen pumping current and $\mathrm{CO}$ partial pressure of the sensor using the $\mathrm{RuO}_{2} / \mathrm{LSC}$ powder-coated $\mathrm{RuO}_{2}$ film electrode is shown in Fig. 8(b). Obviously, the oxygen pumping current monotonically increased with increasing CO concentration. Compared to the slopes of lines in Fig. 5, those in Fig. 8 are much larger at all operating temperatures, and this suggests that the sensitivity of the sensor can be increased by coating the $\mathrm{RuO}_{2}$ film electrode with $\mathrm{RuO}_{2} / \mathrm{LSC}$ powder. For example, the sensitivity to $\mathrm{CO}$ at $673 \mathrm{~K}$ was increased from 12.6 to $19.5 \mu \mathrm{A} /$ decade. Although contact between $\mathrm{RuO}_{2}$ electrode was greatly improved by preparing it using sputtering, the surface area was much smaller than that of the powder-coated one. Therefore, by coating with $\mathrm{RuO}_{2} / \mathrm{LSC}$ powder, reaction sites for CO oxidation can be increased, resulting in increased sensitivity to CO. At 973K, an oxidation reaction also occurred on $\mathrm{Au} / \mathrm{ITO}$, the inactive electrode. Therefore, the difference in $\mathrm{P}_{\mathrm{O} 2}$ between anode and cathode became smaller at excessively high operating temperatures. In any 
case, it is clear that the oxygen pumping current of the sensor with $\mathrm{RuO}_{2}$ and $\mathrm{Au} / \mathrm{ITO}$ film prepared by sputtering can be used for detection of $\mathrm{CO}$ in exhaust gas. Because it is expected that the miniaturization of the sensor may also be easily achieved, reasonable response and high sensitivity of the sensor prepared with sputtering is highly attractive.

\section{Conclusion}

This study revealed that the oxygen pumping current increased with increasing $\mathrm{CO}$ concentration when $\mathrm{Au}(10 \mathrm{wt} \%) / \mathrm{ITO}$ and $\mathrm{RuO}_{2}(10 \mathrm{wt} \%)$ were used for cathode and anode, respectively, and LSGM was used as the electrolyte. In this study, electrodes were prepared by DC sputtering and their sensitivity to $\mathrm{CO}$ was much improved by good contact between electrolyte and electrode. Although the morphology of the deposited electrode film was somewhat dense, the oxygen pumping current in the sensor responded sensitively to CO. Coating $\mathrm{RuO}_{2} / \mathrm{LSC}$ powder on $\mathrm{RuO}_{2}$ electrodes prepared by sputtering is effective for increasing sensitivity to $\mathrm{CO}$ and, considering the sensitivity to $\mathrm{O}_{2}$, the optimum operating temperature seems to be $673 \mathrm{~K}$.

\section{References}

1 N. Docquier and S. Candel: Prog. Ener. Combust. Sci. 28 (2002) 107.

2 B. Bahrami, A. Khodadadi, M. Kazemeini, and Y. Mortazavi: Sens. Actuators, B 133 (2008) 352.

3 L. I. Trakhtenberg, G. N. Gerasimov, V. F. Gromov, T. V. Belysheva, and O. J. Ilegbusi: Sens. Actuators, B 209562 (2015).

4 C. J. Li, M. Lv, J. L. Zuo, and X. T. Huang: Sensors 15 (2015) 3789.

5 N. Miura, K. Kanamaru, Y. Shimizu, and N. Yamazoe: Solid State Ionics 40-41 (1990) 452.

6 T. Hibino, A. Hashimoto, S. Kakimoto, and M. Sano: J. Electrochem. Soc. 148 H1 (2001).

7 N. Miura, G. Lu, and N. Yamazoe: Solid State Ionics 136-137 (2000) 533.

8 E. L. Brosha, R. Mukundan, D. R. Brown, F. H. Garzon, and J. H. Visser: Solid State Ionics 148 (2002) 61.

9 J. W. Fergus: Sens. Actuators, B 122 (2007) 683.

10 J. Wang, P. Elumalai, D. Terada, M. Hasei, and N. Miura: Solid State Ionics 177 (2006) 2305.

11 Y. Shimizu, H. Nishi, H. Suzuki, and K. Maeda: Sens. Actuators, B 65 (2000) 141.

12 N. Miura, T. Raisen, G. Lu, and N. Yamazoe: Sens. Actuators, B 47 (1998) 84.

13 A. Dutta and T. Ishihara: Mater. Manuf. Process. 21 (2006) 225.

14 A. Dutta, T. Ishihara, and H. Nishiguchi: Chem. Mater. 16 (2004) 5198.

15 A. Dutta and T. Ishihara: Electrochem. Solid-State Lett. 8 (2005) H46.

16 A. Dutta and T. Ishihara: Sens. Actuators, B 108 (2005) 309.

17 A. Dutta, H. Nishiguchi, Y. Takita, and T. Ishihara: Sens. Actuators, B 108 (2005) 368.

18 C. Phawachalotorn, O. Sanguanruang, and T. Ishihara: Sens. Actuators, B 161 (2012) 635.

19 T. Ishihara, H. Matsuda, and Y. Takita: J. Am. Chem. Soc. 116 (1994) 3801.

20 T. Ishihara, H. Minami, H. Matsuda, H. Nishiguchi, and Y. Takita: Chem. Comm. (1996) 929.

21 T. Ishihara and J. Iwata: Sens. Actuators, B 223 (2016) 535. 